L. Bannon, I. Wagner, C. Gutwin, R. Harper, and K. Schmidt (eds.).

ECSCW'07: Proceedings of the Tenth European Conference on Computer Supported Cooperative Work, 24-28 September 2007, Limerick, Ireland

(C) Springer 2007

\title{
Seeing Ethnographically: Teaching ethnography as part of CSCW
}

\author{
Barry Brown ${ }^{1}$, Johan Lundin ${ }^{2}$, Mattias Rost ${ }^{4}$, Gustav Lymer ${ }^{3}$, Lars \\ Erik Holmquist ${ }^{4}$ \\ ${ }^{1}$ Department of Communications, University of California San Diego; ${ }^{2}$ IT University Göteborg; \\ ${ }^{3}$ Göteborg University; ${ }^{4} \mathrm{FAL}$ Lab, Viktoria Institute \\ Barry.at.brown@acm.org
}

\begin{abstract}
While ethnography is an established part of CSCW research, teaching and learning ethnography presents unique and distinct challenges. This paper discusses a study of fieldwork and analysis amongst a group of students learning ethnography as part of a CSCW \& design course. Studying the students' practices we explore fieldwork as a learning experience, both learning about fieldsites as well as learning the practices of ethnography. During their fieldwork and analysis the students used a wiki to collaborate, sharing their field and analytic notes. From this we draw lessons for how ethnography can be taught as a collaborative analytic process and discuss extensions to the wiki to better support its use for collaborating around fieldnotes. In closing we reflect upon the role of learning ethnography as a practical hands on - rather than theoretical - pursuit.
\end{abstract}

\section{Introduction}

Ethnographic fieldwork has made a number of distinct contributions to CSCW. Through the in-depth examination of settings, findings have been drawn with implications not only for design, but also more broadly for how technology fits and conflicts with everyday work and leisure. Ethnographic work within CSCW has featured a distinctive focus when compared to traditional anthropological or sociological ethnography, in particular engaging analytic positions that encourage the close attention to the details of activity (Anderson 1994;Button 2000; Harper 2000). Alongside this academic contribution, design ethnography has become an established part of HCI education. HCI textbooks frequently present ethnography 
alongside other methods for evaluating and inspiring technology development. Design education has also taken ethnography to heart - paralleling the way in which design firms such as IDEO have adopted forms of ethnography as part of their consulting toolkit (Wasson 2000).

Yet teaching ethnography as part of design or technical programs presents significant challenges. As a method, ethnography rests considerably on craft and analytic know-how that comes from engaged practice. It is a common observation of methods books that ethnography cannot be learnt from books alone. Moreover, ethnography itself involves learning anew about whatever setting one is studying. Teaching ethnography involves both what ethnography might be and also how to learn and understand the specifics of the setting under study. In this paper we examine these practices of teaching and learning ethnography. We examine how ethnography is learnt and conducted as a practical enterprise, how that might be technically supported, and how it might be better taught. For six years ethnographic methods have taught as part of an IT masters program. As part of this course students conduct two weeks of 'quick and dirty' fieldwork, followed by 3 weeks analyzing their data, writing up and presenting their findings to industrial clients. This fieldwork is then used to design and develop prototype systems. Conducting over 75 days in total of fieldwork, studying the students' work provided a valuable forum to study how ethnography is conducted: both as a way of learning about a setting and as a practice to be learned in itself.

In turn, we discuss tools that can be used to support teaching ethnography. As part of this course we experimented with using wikis (an easily editable website) to support sharing and collaboration around fieldnotes. While having received only passing attention within CSCW (Guzdial and Rick 2000), wiki's are an increasingly popular and widespread collaborative technology. For the students the wiki acted as an 'available anywhere' repository of fieldnotes that had in previous years been private. We discuss two lightweight extensions to the wiki developed to better support their use for collecting fieldnotes and discussion around the fieldnotes.

The paper starts with a brief background to fieldwork as used in the design of collaborative systems, as well as a review of discussions of teaching ethnography, and the specific issues that concern teaching design ethnography. Moving onto studying the students we focus first on the practices of ethnography, giving a broad overview, through the students experiences, of how ethnography is conducted. The second section focuses specifically on the collection of fieldnotes and the use of the wiki to support both co-present and distant collaboration. In the third section we address the students experiences learning fieldwork, describing their learning as a process of 'coming to see ethnographically'. In particular, we focus on the crucible of ethnography - analytic work, and engaging students with moving from procedural understandings to an analytic understanding of ethnography. 


\section{Ethnography in CSCW}

The distinctive nature of fieldwork for design has accumulated considerable commentary as CSCW has developed (Anderson 1994; Harper 2000; Luff, et al. 2001; Sharrock and Hughes 2001). Indeed, there is a not inconsiderable debate about what ethnography actually is, with a range of views on how wide or narrow to define ethnographic practice. As Harper comments, many sociologists use ethnography as a 'catch-all phrase for a range of different things, just as long as they involve field work of some sort' (Harper 2000). Others would restrict the definition - Button in particular criticises 'scenic fieldwork' where fieldwork only 'records what is to be seen' (Button 2000). Whilst located in computer science departments or research labs, design ethnography has not escaped the systemic disputes of the social sciences (Sharrock and Hughes 2001).

One key challenge of ethnography within CSCW is to connect with design with commentary ranging from the prescriptive (Beyer and Holtzblatt 1997) to the reflective (Anderson 1994). Dourish (2006) argues that the significance of ethnographic work is frequently not in how it can influence specific interventions, but more broadly for how it can support understanding and reflection on technological practice. For example, Bowers et al's (Bowers, et al. 1995) discussion of the flow of work in a printing firm is a valuable counterpoint to technologists conceptions of workflow. The value of ethnography here is broader than implications for a specific technology rich though that contribution can be.

A contrasting criticism is that the brevity of CSCW's design ethnographies can seem a deficiency when compared to the longer studies of anthropology or sociology. However, this would be to misunderstand the design ethnographer's job. Design ethnographies do not fail if they do not give an account that will equip an outsider to do that particular job, or even if they do not capture all the essential features of a lifeworld. The orientation of this work instead is to what essential practices have an impact on technological interventions and understanding. This is not simply a documentation of practices, but an understanding of why features and activity are arranged in such and such a way, the resources that are used to do what is done. This is not to downplay the value of time in the field when ethnographers have goals beyond specific designs or validating fieldwork to others (Harper 2000).

Yet while the conceptual or theoretical positions of ethnography have thus scarcely ever escaped debate, discussions of the concrete practical trade of ethnographic study, and the teaching of those skills to others, are more lacking within CSCW. Method textbooks provide valuable introductions to fieldwork and the skills of fieldwork, although in a pedagogical role there is less space for reflection on teaching itself (Crabtree 2003; Randall et al 2007).

Indeed, within CSCW teaching as an activity has been somewhat neglected. The impact of CSCW has been not only in its academic research impact, but in 
the skills it has passed onto non-researchers and those skills carried into distinct workplaces. Indeed, this in some contrast to HCI and Information Sciences, where teaching have played a more prominent role. While textbooks and the like can summarise what is to be learnt, teaching CSCW involves imparting a distinctive attitude - in particular a sensitivity to workplace co-ordination - and no more so than with teaching design ethnography. Ethnography is specifically challenging to teach since it combines a complex of theoretical, analytic, observational and organisational skills. In Weinberg and Stephens' paper on teaching ethnography as part of computer science (Weinberg and Stephens 2002), they discuss how the challenges of teaching ethnography invite reflection onto the practice of professional ethnography itself. Studying the teaching of ethnography is not only an opportunity to examine pedagogy but to look afresh at ethnography itself. Outside CSCW there has been more extensive discussion of how to teach ethnography, with an emphasis on the importance of practical engagement with the activity as opposed to learning through conventional lecture format. Trujillo (1999) discusses going as far as to write and submit academic papers in a research team with his students, embedding their practices of fieldwork analysis and writing into his own professional academic practice. Sotrin (1999) in contrast focuses on the analytic purposes of ethnography - and how students struggle with 'bracketing the familiar' of their commensense assumptions.

Technical support for teaching ethnography is one approach that we have explored here. Systems for tagging data such as HyperResearch and ATLAS-TI have gained some use amongst ethnographers. However, for many these tools remain controversial, in part because of the analytic orientation they encourage, and connections with approaches such as grounded theory and strip analysis (Coffey, et al. 1996). More radically some authors have experimented with using the web to present multimedia accounts of fieldwork and more multi-voiced accounts (Kersenboom 1995), echoing work on the 'designers notepad' that supported richer descriptions of fieldwork as part of the design process (Sommerville 1993). Much ethnographic data itself, of course, is also increasingly collected online from emails, blogs, websites and the like. For the project discussed here we explored the use of wikis as a tool to support students learning ethnography (the focus of (Lymer, et al. 2007)). Wikis are websites which support the editing of pages through the addition of an 'edit' button on each page. Wikis have been particularly successful in the classroom (Da Lio, et al. 2005). The CoWeb (Guzdial and Rick 2000) system, for example, supported co-present learning amongst groups of architecture students, who used the wiki website to share their coursework. Wikis suited our purposes not only because of their simplicity, but also for how they could potentially open up the process of writing and reviewing fieldnotes, a practice we discuss in our results section. 


\section{Studying the studies}

A core part of teaching in the Scandinavian informatics tradition has been to focus attention on users and those that are affected by technology. Over the last five years at the IT University, Göteborg a class in fieldwork has been taught to masters IT students in an attempt to engage the students with a richer sense of the work settings that they design for. To better understand teaching ethnographic practice, how students could learn fieldwork skills, and how to support collaboration, for one class we collected data on the students' experiences of one class. Nineteen students were divided into five project groups each, and engaged fulltime in two weeks of fieldwork, followed by four weeks of analysis and finally writing a report on their findings. All of the groups worked with clients who wanted to study and explore the possibility of supporting a specific practice with mobile technology. The students had been taught basic ethnographic theory and fieldwork techniques, and were familiarisation with methods through conducting a one day study. They students had also been required to take part in reading seminars, focusing on fieldwork papers from CSCW.

In approaching the students work we were conscious that while this was a opportunity to study concentrated fieldwork, the students were not experienced fieldworkers. As Forsythe points out, ethnography is a complex trade (Forsythe 1999) (although this point is frequently laboured). Moreover, as we discuss below the 'students problem' - learning a skill (and passing the course)- was subtly different from that of simply producing a publishable field study. Yet the students dealt with many of the same problems - concrete and conceptual - we ourselves experienced in our own fieldwork. Indeed, the students talked about, and displayed through their learning, aspects that would perhaps have been hidden if we studied experienced fieldworkers, or reflected on our own practices (Ten Have 2003). The friction between the advisors, the students and ourselves was revealing of ethnographic practice (and our own failings and analytic purposes). Our view of the students experiences, as well as the lessons we drew for design, are therefore seen through the prism of our own fieldwork experiences.

The groups studied a wide range of different sites and arranged their own access. Group one studied learning support amongst school children, investigating a local science discovery centre. The second group explored ideas of supporting the mobile repair of trucks, studying repair workshops for trucks, planes and buses. Group three investigated the use of paper within journalism and advertising, studying a newspaper and a photo bureau. Group four looked at how facility management work takes place studying an office building where an external company provided the facility support, and lastly, the final group focused on messenger firms that made daily deliveries by truck and car. 
The main bulk of the students' learning of the practices of ethnography took place in and through the actual carrying out of fieldwork. This means that the content of the course was made visible to the students in the form of real problems, "owned" by the students themselves, rather than as intellectual problems posed as school assignments. For example, facing the awkwardness of observing school kids at a science centre required the students to find ways of dealing with the situation then and there. The students met the problems of ethnographic fieldwork in much the same ways as would a "real" ethnographer. These problems were intended as the main stimulus and focus of student activity; and thus the approach taken was student centred rather than textbook centred (Charlin, et al. 1998).
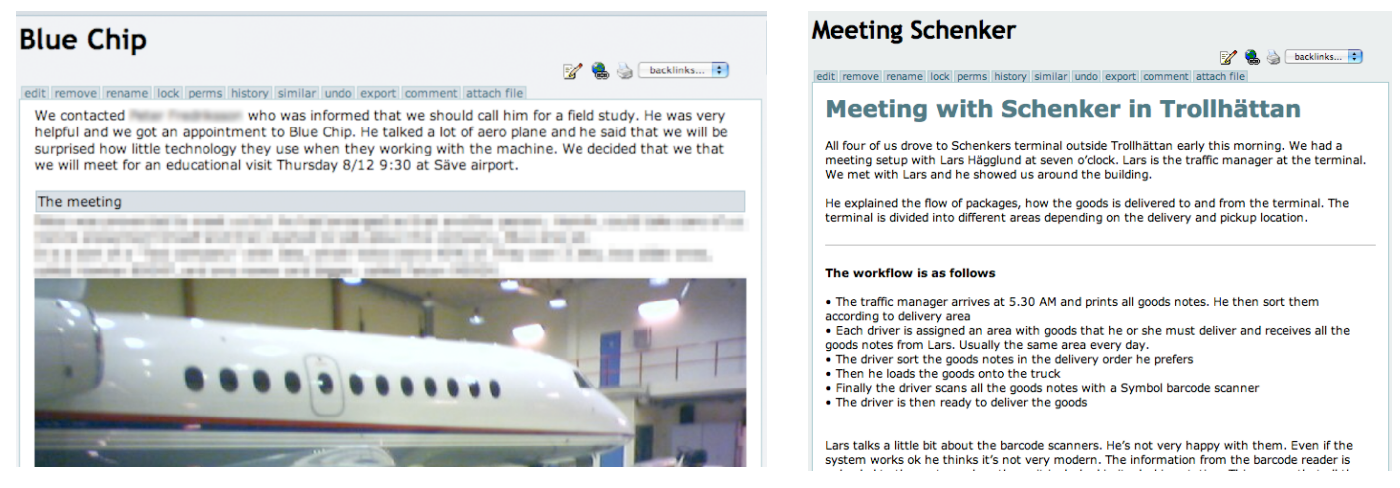

Figure 1. Two fieldnotes from the wiki

Alongside the students' fieldwork we conducted our own fieldwork on the groups' fieldwork. This involved video taping supervisory meetings with the students (ten supervisory meetings in total), video taping three of the students own analysis sessions, and interviewing eight of the students about their experiences in the field. While it was difficult to follow the students conducting their fieldwork, due to access issues, we did video record two days from the group who were studying a local science centre.

The use of the wiki amongst the students also provided a valuable source of $\log$ data on their sharing of fieldnotes. The original aim of the wiki (figure 1) was to allow the students to share their fieldnotes within their fieldwork group. We used the open source 'TikiWiki' (http://tikiwiki.org/) software, one of the most popular free Wiki systems available. Tikiwiki has many of the features of more advance groupware systems such as support for forums, blogs, and even workflow integration. Its ability to password protect pages of the wiki allowed us to support the privacy of fieldnotes amongst the class. We specifically asked the students when gaining access to their field site to specifically ask for permission to share their fieldnotes with advisors and classmates. All groups obtained permission, except one group where the notes were confidential. For all the other groups fieldnotes were left open, editable to ourselves, the respective clients, and the whole of the class. The students were given accounts on a wiki, alongside a 
demo in class, and were asked to enter all their typed fieldnotes into the wiki as the fieldwork progressed. In total over 109 fieldnotes and analytic notes were entered into the system ( 6 per student), distributed over 86 separate pages in the wiki. For the final grade of the ethnographic part of the course the students were simply evaluated in terms of 'pass' or 'fail' -all the students successfully passed this part of the course. While none of the authors were involved in the grading or evaluation of the students work, the second author was involved in a supervisory role discussing with the students their results and fieldwork. The other authors also engaged in helping the students during analysis sessions.

\section{Results}

The first section 'doing ethnography' gives an overview of the ethnographic process, discussing the different stages involved in ethnography. In particular, we highlight the importance of the transformation of data, over than simply capturing data. In the second section 'writing ethnography' we discuss how fieldnotes were collected and shared using the wiki. Lastly, in 'seeing ethnographically', we discuss the students experiences of 'learning ethnography' as a double learning process about both about the setting they were studying, and the practices of ethnography themselves.

\section{Doing ethnography}

While the practices of ethnography will be familiar to many readers, from experience or knowledge of methods, it is worth reflecting on what is involved in ethnography while discussing how the student ethnographers faired. We would argue that much of the social interactional processes of ethnography are glossed by designations such as "getting in", "getting on" and "getting out" (Buchanan, et al. 1988). In particular, while the competencies involved in (for example) impression management are frequently identified in the literature, they are seldom examined in depth as practical mundane activity (Bell, 2004).

Reflecting on the skills of our student ethnographers, we can characterise their ethnography very broadly into five different stages where different activities dominate. In the organisation phase access to the setting is obtained, and the fieldwork organised. Setbacks and contingencies can mean that organisation can be conducted $a d$ hoc as a project progresses. A common piece of advice from fieldwork manuals is to use one's own connections to gain access: an approach followed by the mobile workshop group, who had a member who had originally worked as a mechanic helping them to gain access to his old workshop. More broadly (to our surprise) the groups found little difficulty gaining access - perhaps in part because of their ability to describe their involvement as a 'student project'.

Observation and participation involves making observations and interviews in the setting, alongside participation and prolonged study. Fieldnotes are taken de- 
scribing the setting, as well as photographs, video and audio recordings. The prolonged observation that is key in fieldwork is not an activity that many of us normally do, and it can seem a disturbing and even rude activity. Yet observation is a prevalent part of our everyday lives - we observe what people do when we cross the road or queue in a shop. So many of the mundane practices of observation are those that we know and use as part of our everyday lives. Indeed, even prolonged observation is not that unusual, a newcomer to a job might 'shadow' the employee he is replacing.

The way in which the groups carried out their fieldwork adjusted to the possibilities of the different field sites. With the first group looking at learning, they wanted a high concentration of children engaging in learning. They arranged access to a local science centre, where they followed classes around the centre. Alternatively, the group working with truck repairs visited a number of different workshops on what they called 'educational' visits. This involved observations of groups of workers at different workshops, and trailing mechanics as they went out in the field and worked on repairs.

Central to observation during fieldwork is taking notes. While it might seem a trivial point the form factor of a notebook can have subtle effects on note taking and observation. The students spent considerable time discussing what type of notebook to take. The physical appearance of a paper notebook (and in particular its size) contributes to the 'strangeness' of fieldwork. The format of the notebook also impacts what notes can be taken - a smaller notebook makes it harder to write down long notes, but is more suitable for quickly jotting down short notes. Since note taking has to be done during ongoing activity the ability to take notes quickly is essential.

In the transformation phase the experiences of fieldwork are transformed into materials that are more suitable for analysis. The classic example is the typing up of fieldnotes at the end of each day - where observations are enriched for the record, brief notes taken at the time transformed into longer descriptions augmented with further observations. Transformation can take on other forms such as selecting sections of video, transcribing audio, typing up handwritten notes, making diagrams from photographs etc. Even though this frequently involves the mundane work of transcribing or typing up, it is a crucial stage in many ways. It is not just that the fieldworker is immersing themselves in the data: transformation starts the process of analysis as data is extracted or enriched through rewriting and representation. As one student commented about continually rewriting their fieldnotes:

When I walked with them I tried to write down quick keywords. And then, when I got some time, maybe when we were in the office, I sat down and then wrote what I had seen. But it was kind of sloppy notes, it was difficult to read what I wrote myself. So every night afterwards I wrote out my notes. Then I wrote them in on the computer, and so on.

Analysis can take many different forms based on the orientation of the fieldworker. While the distinctiveness of fieldwork makes it perhaps the easiest part to 
describe and discuss (and in discussions of methods it can often dominate) analysis is the crucible of ethnographic work. Analysis involves taking a stance on those observed and how they engage with the world. In CSCW, and in ethnomethodologically influenced ethnographies such as ours, a key question is how someone can do what they do.

In concrete terms during analysis there was much reading, rewriting, discussion, drawing and reorganisation in the students analysis. Much of the students work was simply extracting, re-representing comparison and re-reading:

After the fieldstudy we wrote everything out and then everyone read the same and marked out those things that we considered relevant... It turned out to be something like 80 or 90 pages.

Broadly the students looked for themes that they could extract from the fieldwork - 'what might be interesting' - drawing as much on the experiences of the fieldwork as the notes themselves. One challenge here was that different fieldworkers had looked at different settings. As one student remarks in an analysis session:

A: You know we have so many different settings, we got the airport, we got the boat testing central, or boat motor test $[\ldots]$

M: Well in that case we might be able to find some common patterns at least [... Or deviant patterns which also would be interesting

For ourselves as analysts studying the students was challenging in that it highlighted our own analytic perspectives, perspectives not always shared by the students. This came to the fore in analysis sessions - the students generally tried to downplay the detail of their own observations, in favour of explanations based around psychology or managerial logic. Students would produce elaborate descriptions of the motivations or desires of those they had observed - projecting needs and cognition onto those they were studying which we argued they had few resources to confirm. Rather than addressing how those being studied did what they did, these explanations addressed more why they acted as they did. In turn, managerialist descriptions came from interviews with management in the studied organisations. In this form of analysis the students repeated management descriptions of problems and practices, at times in direct contradiction to what their own observations showed.

Lastly, in writing up the analysis is written into the final report on the fieldwork. The development of this text often takes place in parallel with the analysis, in that through writing about the data fieldworkers come to new understandings of what is in the data. Writing up thus draws upon transformed documents written in the field, and text produced by the analysis. Within anthropology the writing up phases of fieldwork continues to gain much analytic focus - the ethnographic text, and the presentation of the ethnographer and those studied has initiated much debate (Katz 2000). This has been less of an issue in CSCW, where questions of the writing up phase have mainly engaged with the specific design colour of CSCW: fieldwork may end up being presented to designers, and results worked 
through with designers to connect findings with those concerns. This can involve the ethnographer working as some sort of proxy for the user, or alternatively as a designer themselves. As we have mentioned, the nature of this interface is a recurring theme within $\mathrm{CSCW}$ and related fields. In the final reports it was clear that all the groups engaged in original ways with their fieldwork. One group's client, the mobile truck repair group, set the group the task of designing support for the repair of trucks at the side of the road rather than in a workshop. However, the groups' fieldwork questioned the need for this, and with the client's agreement they instead built a system that supported deciding when to repair a truck outside the workshop.

While we have set out ethnography and the students work in terms of a set of stages, they are more schematic holders for the practices of ethnography. In common with many other complex endeavours these activities span across different stages, and need not follow each other in a linear pattern. After all, ethnography is by its very nature a discovering practice - one does not know the end result until one gets there. It is a commonplace observation in the methods literature and confessional ethnographic accounts (Van Maanen 1988) that the retrospective accounts given in methods descriptions have only a schematic similarity to research as a prospective concern.

\section{Writing ethnography}

Fieldnotes are a central part of ethnographic practice, and have attracted attention in themselves with a number of volumes discussing how and what fieldnotes might be (Emerson, et al. 1995). Alongside their analytic and ethnographic work, the groups made heavy use of fieldnotes to discuss the settings. However, as we have remarked above, these fieldnotes were also shared amongst the class through a wiki. As experienced fieldworkers we had our own sensitivities to sharing fieldnotes, particularly in a system where the access to the fieldnotes was deliberately open. However, all the students typed up all their fieldnotes and put them online. At its peak, students were reading an average of 26 pages a week each, dropping to 7 in the week before they submitted their reports. Each student also entered an average of 6, usually lengthy, fieldnotes into the wiki. A number of students also collected photographs from the fieldsites, annotated those photographs, and interested them into the text. The flexibility in which photographs could be inserted into text supported reference to specific aspects of the photographs in the fieldnotes. The elaborate nature of the fieldnotes created by some of the students with mixes of scanned documents, photos and text - suggests that the notes were not just produced for the author, but for other readers. The history of classroom wiki systems contains many failed systems (Guzdial and Rick 2000) and one could imagine a sensitivity to sharing fieldnotes preventing use of the system. As we had not set submitting fieldnotes as a requirement for the course, this comprehensive entering of data was noteworthy. 
As described by (Scribner and Cole 1981), transforming the practices and technologies surrounding writing can have general consequences for how participants relate to text, and for the skills and competencies that are engaged with and learned. Although Scribner \& Cole refer to more large-scale differences in literacy practices, a change as local and small scale as the introduction of a wiki - and the associated practices of writing that change along with it - could nevertheless have consequences that go beyond the mere organisation of textual work. With the students, one function of the wiki that became apparent was the way in which it supported and encouraged students' orientations towards relevant practices and competencies involved in fieldwork.

That is to say, the sharing of fieldnotes provided awareness amongst the students and advisors of each others' 'hidden work'. Fieldwork was mostly conducted individually. In the interviews the students talked about reading each others fieldnotes to get a sense of 'what a fieldnote was'. This was confirmed by the website logs which showed students reading each others' fieldnotes. Putting field notes into the wiki thus made individual member's production and work visible, both to other group-members and to the advisors. This also made non-use of the wiki visible and publicly accountable. The edit history on particular pages also made visible when others edited fieldnotes, and we noted that fieldnotes on the whole remained single authored, with little collaborative editing of notes.

The availability of fieldnotes was particularly valuable for supervisory meetings. Beginning each session with knowledge of students' work proved beneficial, as teachers knew what students were doing even in the absence of any submitted texts. Analytic notes posted by students would show, for example, how groups had analyzed their fieldnotes, the analytic concepts they had in play. For the instructors they could then respond to the students' choices of categories and strategies, seeing them for the ways in which they differently measured up to the sought after brand of design-oriented fieldwork. This instructive function of the open access to fieldnotes hinged on the responsive nature of teaching; teachers and students, that is, "interpret each others' actions and make, what seems to them, relevant responses" (Dyson 1999, p144). Just as students had access to disciplinary knowledge through the supervisors' instructions, the supervisors gained access to a context in which to formulate instructions through students' actions. The teacher could respond directly to students' own products, counter students' formulations of their own work, seeing in their notes qualities that they themselves had not the ability yet to see.

The effects of having an open collection of fieldnotes also supported students reading each others' fieldnotes and bringing their own notes into alignment with each other. One practice that spread from group to group, for example, was putting times to the left of each paragraph in the wiki, time-stamping different observations. A number of students also used 'smileys' and other email shortcuts, styles that they later went back and deleted as they found that others took a more 
serious tone in their notes. The shared fieldnotes also supported a 'ratchet effect' increasing the expressiveness of the students' fieldnotes. The students could learn from each others' fieldnotes what sort of things could constitute an observation. As with any practice is not simply one of coming into alignment with other students. The teachers endeavoured to review and comment on notes so as to guide the students so as to examine the better quality fieldnotes, and to emulate the best observational practices, rather than simply come to some average.

At times, though, less desirable practices spread between fieldnotes because of their perceived suitability - e.g. colour coding of fieldnotes according to importance featured in groups of students' notes. Moreover, the wiki proved less flexible in allowing teachers to comment on notes. As the only way to comment on fieldnotes was through editing the fieldnote itself, the supervisors felt it inappropriate to directly comment or edit the fieldnotes and instead commented on fieldnotes in the supervision meetings. As the teachers read all the fieldnotes this was perhaps a missed opportunity.

The fieldnotes in the wiki displayed a feature distinct from publicly available Internet wikis. The fieldnotes were not written as objective records of the fieldwork (if ever such a thing was possible). Rather, they were fieldnotes that made sense to their likely readers - predominantly the author of the fieldnote, but also the group of students collaborating in studying that particular fieldsite. Many of the details, jargon, names and such like would make sense to those involved in the fieldsite, but to ourselves and the advisors were much more opaque. The fieldnotes were written for situated reading. Unlike wiki pages written for 'anyone likely to read them' (for example wiki pages publicly available on the internet) these pages were written with a great deal of knowledge about their audience. In this aspect the fieldnotes have many similarities to other forms of record keeping studied within CSCW, in particular medical notes (Heath and Luff 1996). For example, the notes of the group studying the science center assume knowledge of the different exhibits, and how they were used:

He walks over to the mobilia exhibition and clicks on the beard and glasses for half a minute. He seems bored. He walks into the color room and stays there for a minute or so. He comes out and watches a couple of girls and a guide while they play around with the nail rug.

This presented the 'outsiders problem' for ourselves as researchers using the fieldnotes. Often we could not understand fieldnotes, and without access to the situation in which they were produced (e.g. the exhibits) the fieldnotes were little help in understanding the fieldsite. The fieldnotes did not therefore stand as an objective resource for understanding the fieldwork, they were instead collaborative resources embedded in the conduct of group fieldwork.

A last point we will draw out about the use of fieldnotes concerns the use of the wiki as a co-present resource in the students interactions. As mentioned in the introduction to this paper, recently wikis have gained attention for their use as a distributed collaborative tool. Yet the students were co-present in the same uni- 
versity setting, and could easily meet to discuss their fieldwork, their use of the wiki and their fieldnotes. In these meetings the wiki pages were used as a physical resource to be drawn upon. The students printed out a large number of the pages of the wiki, and these would be distributed as they talked about their fieldwork.
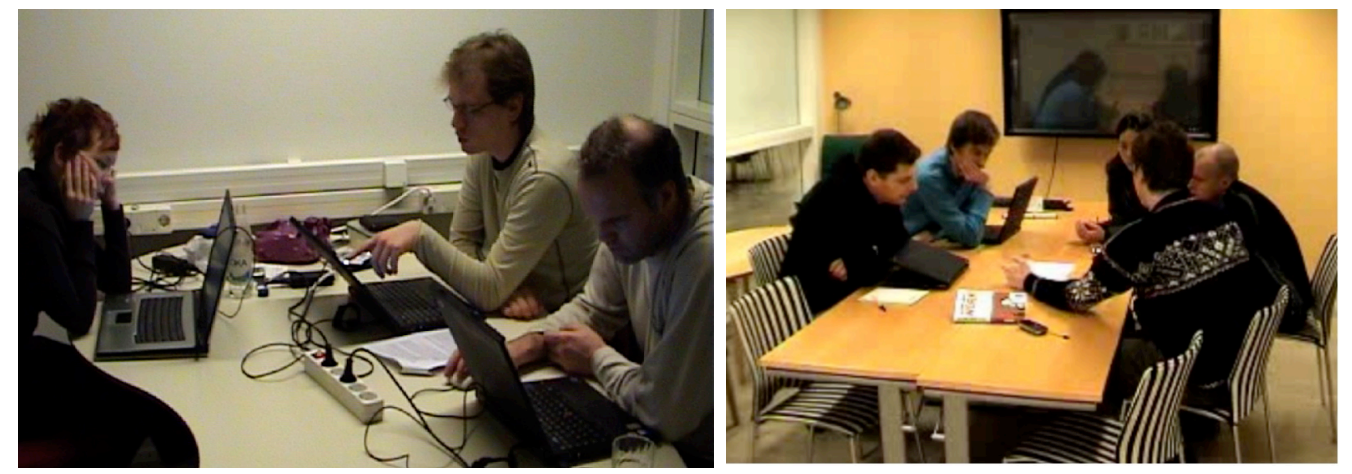

Figure 2. Students in an analysis meeting sharing and talking around viewed wiki pages on their laptops and printed out.

Moreover, since the wiki pages were available online and all the students had laptops (rented to them as part of the program), the students would open specific wiki entries on their laptops as reference in conversation. This occurred particularly during analysis and writing fieldnotes would be 'talked up', read by the author and explained in the meeting and the relevance established for the writing and analysis. Since the wiki pages were commonly available, the student would talk around fieldwork notes read in common on their own laptops. While this sort of discussion could quickly and effectively sort out and ground discussion it left no traces in the wiki. As time went on this meant that the fieldnotes become less relevant since they did not contain discussions that worked up the fieldnotes' relevance. However, the students did keep notes from their meetings that they typed into the wiki as analytic notes. This meant that in the wiki alongside the fieldnotes the analysis process was partial documented.

\section{Seeing ethnographically}

With this schematic description of the students practices in place we can now engage more closely with the learning experiences of the students - in particular how they came to develop an ethnographic sense of what might be an interesting finding. As we have mentioned, we do not wish to overplay the similarities between the students work and the work of professional ethnographers. Indeed the students 'problem' in studying and conducting ethnography was subtly different from that of professional ethnographers. First, the students had to study the setting itself, and learn from those in the setting what was involved in doing that particular job. This was not simply learning about a site or simply collecting facts from 
the field: the students had to learn 'knowing-in-action' - the knowing inherent in competent and valid action in the setting. Second, the students were also learning the specific practices of fieldwork and ethnography. Since the students were conducting fieldwork as part of a course, there was a concern for producing the 'right' ethnography - not simply decoding ethnography as some sort of abstract process, but as what they could do to get them successfully through their course.

The skills of learning about a setting and the nature of that setting are interconnected. Ethnography is not the same in different arenas: an ethnographer must adjust their methods to each setting and in a sense learn the skills of ethnography afresh. An ethnographer does not observe in exactly the same way, or the exact same order every time. That ethnography cannot be learnt from a book is therefore not a mysterious but a very practical point: only by engaging in the adaptation of methods to a setting - and at times failing to understand a practice- can one come to learn what is involved in an ethnographic study.

The first part of the student's problem was to recognise, in the field, what might be something of interest for the research. We would liken the process of learning ethnography to that of 'learning to see'. In Goodwin's studies of professional vision (Goodwin 1994) he explores how it is that the work of professionals is often organised around their ability to see aspects of the world that we cannot normally see. Goodwin takes vision and rather than treat it as a cognitive ability of particular individuals, documents it as a socially organised professional practice. So, for example, in his study of archaeologists he showed how they can see colour differences in a sample of soil as suggestive of a particular historical artefact. While an uneducated observer may only see numbers on a computer screen, a professional oceanographer may see these as a 'nice' feature of a particular flow of seawater. Seeing for scientists and archaeologists is something that is learnt through instructed seeing - through the highlighting of signs and objects in fields - moving from figure to ground.

The work of the students in learning ethnography was in many ways learning to 'see ethnographically'. The students had to find, from each confusing fieldsite what was a 'feature' - what was something that could be discussed. To make this problem more complex, the students not only had to understand what might be an interesting feature, but had to do this through the participants point of view - how did they themselves organise their seeing, rather than (say) taking the descriptions given by their managers. This involved recognising what the objects and people did, and what relevance those people and objects had. For example, for the group studying truck repairs, they had to learn to see the different urgencies of different truck breakdowns, how truck repairs were scheduled, and the importance of that schedule in providing a good service.

In analysis meetings relevant categories would be highlighted by the supervisors from relevant 'features' in the data. Yet the students still struggled in understanding what aspects these 'features' had in common, and why those features 
had been chosen as of interest. It was only when the students later came to analysis that the relevance of particular findings were shown. In this way the students struggled with the documentary method of interpretation (Goodwin 1994). The highlighting of a feature in a field site goes on to highlight that feature and contrast it with other less interesting parts of the fieldwork. That in turn sets up a context of relevance - other parts of the fieldwork can be seen in relation to that feature and the parts can be seen to illustrate the original.

Another example: in one meeting the students discussed how the delivery drivers they were studying arranged and re-arranged the route they took when delivering packages. Often a new urgent package would come into the depot during the day, and the drivers had to go back to the depot to collect and then deliver that package. To deal with this the drivers would call up other drivers, even from competitor companies, and ask them to deliver their existing packages while they went back to the depot. On hearing this during an analysis session the advisor marked this out as a 'feature' - and described it as an example of 'cooperation within the profession'. He then urged the students to look at other examples of the drivers cooperating across companies. This feature structured the domain of scrutiny - it became one of 'driver collaboration', and other features could be picked out from the study with reference to 'driver collaboration'.

Alongside being able to 'see' features in the data, the students needed to be able to render those features in ways of interest. Goodwin points out the importance of graphical representations as ways of structuring, recording and communicating the features that are part of professional work. In the case of the students the problem was not so much graphically as textually rendering what they found in ways that were of interest. The first fieldnotes they produced were merely descriptions that missed out much of the interaction and details of the work. They produced maps of where things were, descriptions of what was done where - descriptions which focused on what people did rather than how they did their work (in contrast to (Katz 2000)).

This all said, we would not want to describe the students' emerging analytic skills as simply those of identifying and rendering 'interesting' observations. The development of seeing ethnographically, as we have put it, involves a growing sensibility in the observer - seeing not only that those events are interesting but that they cut with the problems of those involved in making sense of and acting in that social world. This in part involves drawing on an analytic approach, our own draws heavily on ethnomethodology, so as such we encouraged the students to draw on familiar analytic tropes, such as the procedural nature of work tasks or the importance of everyday routines. Yet we also wanted the students to move beyond cookie cutter analysis to creatively engage with what they saw - to generate understandings that came not from simply parroting theory but rather to form insights into the seen yet frequently unnoticed. Ethnomethodology is distinctive here in its focus on the description of practical action. This is not to say that the 
students could not have made work out of other analytic approaches, but our attempt to sensitising them alongside their short training in ethnomethodology, meant that they especially focused on these ordinary workplace methods.

Yet in common with teaching other complex activities that rely upon insight, the crux of the matter for analysis is not to rely upon the theoretical, but to move and differentiate with what each individual setting demands and teaches. We sought to tutor the students moving from the procedural to the insightful. That involves, drawing on Randall et al (2007), an ethnographic design sensibility where in a particular case one can engage with what is happening, but also turn in a manner that makes design possible - that can start the process of creative engagement with particular members' problems, or inventing new forms of using technology and working. In this sense their work was interdisciplinary, but this would somewhat over academicaise their practices - rather their problems were uncovering 'whats and hows' that had relevance for later design. The problem of design relevance then was one that needed to be managed in each analytic moment - moving from 'interesting observations' to analytic finding.

It was in this work that the students developing professional competence could be seen by ourselves and the teachers in their ability to see and talk about our discipline's workaday objects - in this case interesting ethnographic findings. While we have referred to Goodwin focus on vision per se, the instructive practices he describes more broadly - what he calls "the interactive organisation of apprenticeship" (Goodwin 2007, p57) - demonstrate how interaction can be pedagogically by virtue of developing shared orientations to common "domains of scrutiny". So while it may seem unusual to summarise the ethnographic skills of our students in terms of 'seeing' this focuses our own analytic attention on this first important analytic steps. Of course, these seeings are only the start of analytic work, yet this crucial skill crystallised the many different skills the students needed to learn and engage with.

\section{Discussion}

Documenting this course and the students work gives us an opportunity to reflect on aspects of teaching ethnographic work. One distinctive aspect of the course we studied was the almost luxurious time given to the students to learn ethnography. Perhaps more distinctive, however, was the focus on letting students conduct ethnography 'all the way through' - going into the field, engaging with a domain of practice, interacting with more experienced fieldworkers, and writing this up as a report. In the field (as well as in analysis) the students needed to work out themselves how to proceed. Indeed, even the advisors and ourselves needed to learn each different, and new, setting and how it could be approached. This gave students not only an opportunity to learn methods but also a sense of why ethnography is the way it is, and the complexities (and value) of practices that can be uncovered. The shared nature of the fieldwork experiences - supported by the 
shared wiki and analysis sessions - opened up the experiences for reflection by both students and teachers. Since the teachers could see the fieldnotes as they were entered, they could comment and observe, crucially making their observations relevant to where the students were now, not just where the teachers intended to take the class. This also supported interaction and input between students. However this seldom took the role of direct interventions in each others work; rather it was a 'ratchet' effect of students exploring and seeing others practice and attempting to emulate this in their own work. As we mentioned however this could cause problems if unhelpful practices were duplicated.

In terms of concrete lessons for the teaching of ethnography we make three points. First, ethnographic courses should include as much as possible, a focus as much as possible on practical ethnographic and analytic skills. While it is certainly easier for those teaching courses to rely upon the conventional lecture format (of which we have been guilty ourselves), much of the essence of ethnography can be lost. As we have documented, with support students can engage with settings and learn practical and analytic skills. Second, we would argue for the value of an open resource of fieldnotes and analytic notes. In our case the wiki supported a range of rich interactions around fieldnotes that helped support the learning process and allowed better support by supervisors. Lastly, we would suggest that the teaching of ethnographic practices is conducted over sufficient time to support a supervised iterative engagement with the setting. Obviously, it would be impractical for many courses to have as lengthy a ethnographic component as this case, yet having an iterative engagement over time is important to allow students to make mistakes, return to their material, and be supervised during this process.

Perhaps most important of all, the study underlines the value of teaching ethnography as part of CSCW. While the students did not become expert ethnographers in two months, they gained a much deeper understanding of how to engage with understanding a setting, before coming to think about design. This is perhaps the most important student outcome and a core lesson of CSCW - the connected nature of the technical and the social. We have discussed this in terms of students 'coming to see' ethnographically. The joint analysis sessions that were run with the students were most valuable for this, in that the students and advisors shared the work of going through the data trying to understand what might be interesting about the practice under study. The students' final reports demonstrated a subtlety of understanding about how work is engaged with and carried out in the different settings under study something missing from the initial fieldnotes. Perhaps more important than the method per se, the course engaged the students with understanding the complexities of work practice: a valuable input into their future technical careers. This we saw as the real contribution of our teaching: how our students began to see what ethnography might be and how they might systematically understand others' lifeworld, and design taking that into account. 
Although we have focused in this paper on the teaching experience around ethnography, we have explored how to better support technically the students collaboration around fieldnotes and wiki entries. The wiki provided considerable support for co-present interactions around fieldnotes. However, there is currently little support for commenting and annotating pages. This meant that for teachers (and at times even for the groups themselves) it was not easy to comment on fieldnotes apart from actually editing the notes. We have recently added this ability within our wiki to produce a more multi-layered text by attaching notes to areas in the wiki text commentary can be added to fieldnotes, or any wiki pages, without editing the pages themselves. This also supports a form of 'anchored chat', in that conversations can take place around fieldnotes in the notes.
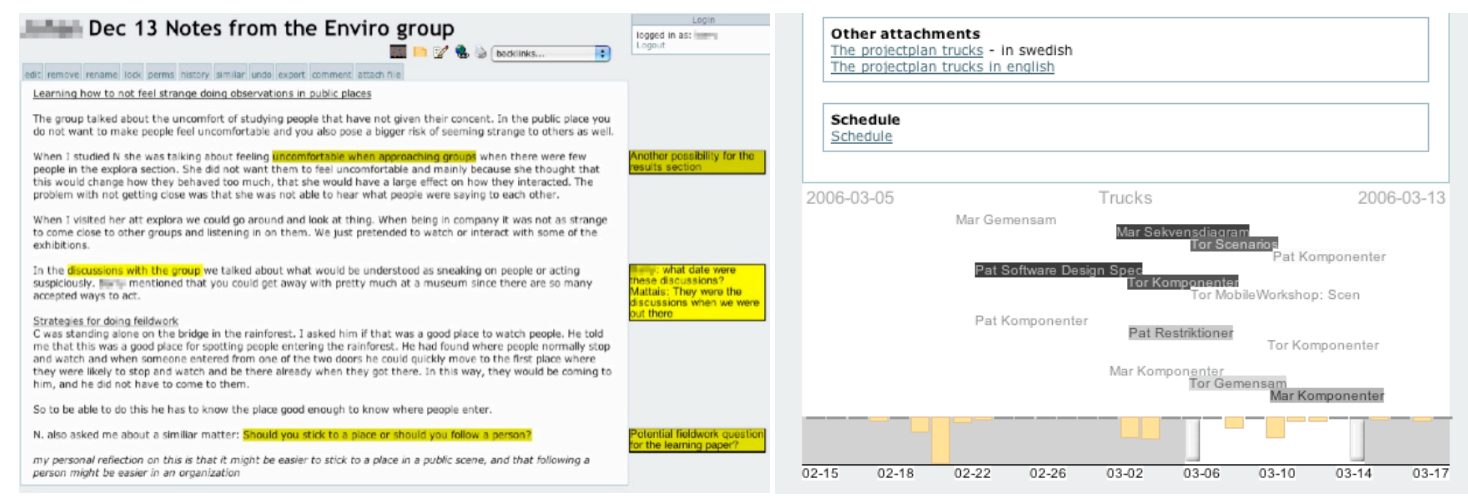

Figure 3. Screenshots from the extensions to the wiki. The text notes allows annotations to be made to the text, while the awareness tool provides an overview of who has edited the wiki and when.

Second, we wanted to address the need for better awareness of the group's activity - a common problem addressed by awareness displays. From the study we could see that reading and noticing others fieldnotes allowed for self-assessment of progress with students comparing their progress to the class. To support this we have designed an awareness display that shows who has edited what allowing editors to compare their own level of contribution to others.

\section{Conclusions}

The focus of this paper has been on a practice well known to CSCW practitioners. Through studying the attempts of a class coming to learn those practices, we have attempted to cast new light on what is involved in fieldwork, both the mundane practices of organisation, note taking, observation, and analysis, but also the analytic skill of 'coming to see'. We have explored at length one class, using their experiences to both describe ethnographic practice, but also how ethnography can be taught as part of CSCW classes. 
Teaching any practice is an opportunity to reflect upon that practice and its conduct. A secondary theme of this paper has been to explicate some mundane practices of ethnography, and to invite reflection on the distinctive practices of ethnography as part of CSCW. In particular, the experiences here with sharing fieldnotes are suggestive broadly of how better to support the collaborative practices of design ethnography. We in turn also offer this as a contribution to ongoing debates concerning the status of design ethnography - emphasising the grounded and methodical practices of insight that ethnography feature. In closing, ethnography is a complex professional practice of which collaboration is a key part. In this paper we have explored how ethnography is not only a key part of $\mathrm{CSCW}$ - as a core method and approach - but as a potential site for enhancing the teaching of $\mathrm{CSCW}$, and engaging future practitioners and academics with the nature of work practice and design.

\section{Acknowledgements}

The work discussed in this paper was supported by the Wallenberg Global Learning Network II. The authors would also like to thank the students who took part, Alexandra Weilenmann for her help and insights during the project, and Eric Laurier for comments on an earlier draft.

\section{References}

Anderson, R. J. (1994): Representations and requirements: The value of ethnography in system design. Human-computer interaction, Vol. 9, pp. 151-182.

Bell, E. (2004): The negotiation of a working role in organisational ethnography. International Journal of Social Research Methodology, Vol. 2, no. 1, pp. 17-37.

Beyer, H. and K. Holtzblatt (1997): Contextual Design : A Customer-Centered Approach to Systems Designs. Morgan Kaufmann Publishers.

Bowers, J., G. Button and W. Sharrock (1995): Workflow from within and without. In: Proceedings of ECSCW '95. Stockholm, Sweden: Kluwer Academic Publishers.

Buchanan, D., D. Boddy and J. McCalman (1988): Getting in, getting on and getting back. In: Doing research in organisations. Routledge.

Button, G. (2000): The Ethnographic Tradition and Design. Design Studies, Vol. 4, no. 21, pp. 319-332.

Charlin, B., K. Mann and P. Hansen (1998): The many facets of problem based learning: A framework for understanding and comparison. Medical teacher, Vol. 20, no. 4, pp. 323-330.

Coffey, A., B. Holbrook and P. Atkinson (1996): Qualitative Data Analysis: Technologies and Representations. Sociological Research Online, Vol. 1, no. 1.

Crabtree, A. (2003): Designing Collaborative Systems: A Practical Guide to Ethnography. Heidlberg: Springer.

Da Lio, E., L. Fraboni and T. Leo (2005): TWiki-based facilitation in a academic community of practice. In: Proceedings symposium on Wiki technology. ACM Press, pp. 85-111.

Dourish, P. (2006): Implications for Design. In: Proceedings of CHI 2006. ACM Press.

Dyson, A. (1999): Transforming transfer: Unruly children, contrary texts, and the persistence of the pedagogical order. Review of Research in Education, Vol. 24, pp. 143-171. 
Emerson, R. M., R. I. Fretz and L. L. Shaw (1995): Writing ethnographic fieldnotes. Chicago University Press.

Forsythe, D. (1999): "It's just a matter of common sense": ethnography as invisible work. Computer supported collaborative work, Vol. 8, no. 1-2, pp. 127-145.

Goodwin, C. (1994): Professional Vision. American Anthropologist, Vol. 96, no. 3, pp. 606-633.

Goodwin, C. (2007): Participation, stance and affect in the organisations of activities. Discourse and Society, Vol. 18, no. 1, pp. 15-73.

Guzdial, M. and J. Rick (2000): Recognizing and Supporting Roles in CSCW. In: Proceedings of CSCW 2000. ACM Press, pp. 261-268.

Harper, R. H. R. (2000): The Organisation in Ethnography: A Discussion of Ethnographic Fieldwork Programs in CSCW. Comput. Supported Coop. Work, Vol. 9, no. 2, pp. 239-264.

Have, P. T. (2003): Teaching students observational methods: visual studies and visual analysis. Visual Studies, Vol. 18, no. 1, pp. 29-35.

Heath, C. and P. Luff (1996): Documents and professional practice: bad organisational reasons for good clinical records. In: Proceedings of CSCW'96. ACM, pp. 354-363.

Katz, J. (2000): From How to Why: On Luminous Description and Causal Inference in Ethnography. Ethnography, Vol. 2, no. 4, pp. 443-473.

Kersenboom, S. (1995): Word, Sound Image: The Life of the Tamil Text. Oxford: Berg.

Luff, P., J. Hindmarsh and C. Heath (eds.) (2001): Workplace studies: recovering work practice and informing system design. Cambridge University Press, Cambridge, UK.

Lymer, G., J. Lundin, B. Brown, M. Rost and L. E. Holmquist (2007): Web based platforms in colocated practice - The use of a wiki as support for learning and instruction. In: Proceedings of CSCL 2007. Lawrence Erlbaum Associates, In Press.

Maanen, J. V. (1988): Tales from the field: on writing ethnography. Chicago: University of Chicago Press.

Randall, D., R. Harper and M. Rouncefield (2007): Fieldwork for Design: Theory and Practice. London: Springer.

Scribner, S. and M. Cole (1981): The psychology of literacy. Harvard University Press.

Sharrock, W. and J. A. Hughes (2001): Ethnography in the workplace: Remarks on its theoretical bases. Team Ethno, Vol. 1, no. 1.

Sommerville, I. (1993): Integrating ethnography into the requirements engineering process. In: Proceedings of the international symposium on requirements engineering. Los Alamitos, Calif.: IEEE CS Press.

Sotirin, P. (1999): Bringing the outside in: ethnography in/beyond the classroom. In: Proceedings of the annual meeting of the national communication association.

Trujillo, N. (1999): Teaching ethnography in the twenty-fifth century using collaborative learning. Journal of contemporary ethnography, Vol. 28, no. 6, pp. 705-719.

Wasson, C. (2000): Ethnography in the field of design. Human Organisation, Vol. 59, no. 4, pp. 377-388.

Weinberg, J. and M. Stephens (2002): Participatory design in a human computer interaction course: teaching ethnography methods to computer scientists. In: Proceedings of SIGCSE 02. ACM Press, pp. 237-247. 